\title{
Excerto de Inventory / Inventário
}

\section{INVENTORY}

We believed in nothing

the black and white american movies

buried themselves in our chests,

glacial, liquid, acidic as love

the way to Wyoming, the sunset in Cheyenne, the surreptitious cook fires, the uneasy sleep of cowboys, the cactus, the tumble weed, the blankets, the homicides of Indians, lit, dimmed, lit, dimmed

lit in the drawing rooms, the suicides inside us

and the light turnings to stone, inside and out, we arrived spectacular, tendering our own bodies into dreamery, as meat, as mask, as burden 
like chaos,

all the fake feelings we had, oh love, the acts of ventriloquism, the wooded arteries, the arms clattering to the floor, the big raw cities flailing us

we returned home dead on our feet and melancholy

the earth was never the earth, we were never anyone, everything we were preceded us, foolish in the heady days when we thought we might, somehow within a few seasons, after their laughter and raucid whistles but this was their manifesto, and we took it like fun the burnt kernels, the chemical sugars 
their love stories never contained us, their war epics left us bloody

we poor, we weak, we dying

we cheered them,

encouraged them, helped them with the cooking, the tracking to our throat lines, gave them the books of signs, the last magical bird feather the traces of our fires

the screens lacerate our intimacies gathered at the windows

on the corners, thinking one day

we'll make it, delicately, without a war, without the tragedy

of it all and maybe with our bodies, though now

it's too late for that 
We waited, we waited stick-like and nervous, did what we could when allowed

made up all the dances, fine, burned our lungs on music, so many dead musicians, the extraterrestrial neurons, the brittle veins it took to leave so much music, so much music, so much dried muscles at olympian lines, the heels eviscerated with speed

and all the folded linen all the broken fingers, pricked and bruised, misformed ribs and the famished babies for the worlds most famous photos

the steel we poured, the rivets we fastened to our bare ribs like cars we stripped, so fastidious, the seams of dirt excised from apples and gold 
all the railways

everywhere, and the forests we destroyed, as far as

the Amazonas' forehead, the Congo's gut the trees we peeled of rough butter, full knowing, there's something wrong with this

then the prison couture of orange clad criminals we became, the kinkiness of blindfolds we admitted

we did all this and more

there were roads of viscera and supine alphabets, and well, fields of prostration

buildings mechanized with flesh and acreages of tender automobiles

heavy with our tiredness, solid with our devotion 
after work we succumbed

headlong in effusive rooms

to the science fiction tales of democracy

and to their songs,

come gather round people for the times

say it loud and when you talk about destruction

count me out deep in my heart I do believe

oh lord won't you buy me make me wanna holler

that's fine, got drunk, got high,

said we were already living in another time

they waited, watched, evacuated all our good lyrics

of the goodness, of the science, the delicious

being of more than, well more,

so hard now to separate what was them

from what we were 
how imprisoned we are in their ghosts

how in their beginnings and endings

no wonder, no wonder,

every evening falls on axioms

the violins of edible fears

someone enters in black, oh darling, oh love,

the eclipses of windowpanes,

the secret life of the sun's corona going by

the woman is lying in the alleyway

treacherous and naked once more,

half the mind is atrophied in this, just as inanimate doorways and pick-up trucks, the unremitting malls of all desires 
small years, small for the distancing planet, how would we know, so suspended, defenseless with our hungers, nibbling our own hearts to the red pits how would it truly be to have danced with Celia Cruz, unsmiling

to have studied instead the street names of Montevideo or Havana, Kingston and Caracas as if planning to live there in the elegant future, as if no other life would do, or if the vows of transformation were only made in Parral or Basse-Pointe

to have loved instead te recuerdo Amanda, la calle mojada, corriendo a la fabrica la lluva en el pelo, to sing this to potential lovers 
then to have seen Che

Guevara as an old man on television,

Angela's unbreakable voice has made jails extinct, to die in this compassion, to have never heard Redemption Song, so hoarse, at all

not willing another empire but history's pulse

measured with another hand, as continents roll over in their sleep

a whimsical contraption moved with sometimish winds

of inconvenient magnets to allow

unpredictable openings of incurable light

now we must wait on their exhaustion, now

we have to pray for their demise with spiked hands, with all the brilliant silences, to understand the whole language, the whole immaculate language of the ravaged world 


\section{INVENTÁRIO}

Não acreditávamos em nada

os filmes americanos a preto e branco

enterravam-se em nós, glaciares, líquidos, ácidos como o amor

o caminho para Wyoming, o pôr-do-sol em Cheyenne, os churrascos clandestinos, o sono

inquieto dos cowboys, os cactos, a salsola seca, os cobertores, os homicídios dos índios, luz, escuro, luz, escuro

as salas iluminadas,

os suicidas dentro de nós,

e as luzes transformando-se em pedra, por dentro e por fora, chegávamos vencedores, alimentando os nossos corpos de sonhos e fantasias, como carne, como máscara, como fardo 
todos os sentimentos falsos que tínhamos, amor, os actos de ventriloquismo, as artérias enrijecidas, os braços arrastando-se pelo chão, a agressão das cidades largas e nuas

regressávamos a casa os pés exaustos

exaustos de melancolia

a terra não foi nunca a terra

não fomos nunca ninguém, tudo o que fomos nos precedeu, loucos que éramos nos dias inebriantes, quando achávamos poder, de alguma maneira, e passadas algumas estações, depois das gargalhadas e roucos assobios

mas este era o seu manifesto, e nós não lhe prestámos atenção, os núcleos queimados, os açúcares químicos 
as histórias de amor deles nunca nos incluíram, as suas guerras épicas deixaram-nos cobertos de sangue,

e nós, pobres, fracos, moribundos

nós aclamámo-los,

encorajámo-los, ajudámo-los na cozinha, e a encontrar os trilhos para as nossas gargantas, demos-lhes os livros dos signos, a última pena de pássaro mágica, o local das nossas fogueiras

os ecrãs ferem-nos as intimidades colhidas às janelas

pelos cantos, pensando que há-de chegar o dia em que o havemos de fazer, delicadamente, sem guerra, sem tragédia nenhuma, talvez até com os nossos corpos embora agora seja já demasiado tarde 
E esperámos, esperámos hirtos e nervosos, fizemos o que podíamos quando nos deixavam

inventámos todas as danças, isso, muito bem, queimámos os pulmões ao som das músicas, tantos músicos mortos, à custa de neurónios extraterrestres, de frágeis veias, o que custou deixar tanta música, tanta música, tantos músculos endurecidos nas pistas olímpicas, os calcanhares destroçados pela velocidade

e toda a roupa dobrada, todos os dedos partidos, picados, doridos, as costelas deformadas e os bebés esfomeados para as fotografias mais famosas do mundo o aço que vertemos, os rebites que apertámos nos nossos ossos nus como nos carros, desfizemos, minuciosamente, as costuras de poeira arrancadas às maçãs e ao ouro 
em todas as linhas de comboio

em todo o lado, e as florestas que destruímos, até lá longe,

à fronte da Amazónia, às entranhas do Congo, as árvores tropicais a que tirámos a pele áspera, sabendo perfeitamente, alguma coisa está mal

depois a prisão de alta-costura em tons laranja dos criminosos em que nos transformámos a perversão dos olhos vendados que aceitámos

fizemos tudo isto e muito mais

estradas de vísceras e arrogantes alfabetos, e, bom, campos de prostração, edifícios mecanizados com carne e largas áreas de frouxos automóveis carregados com o nosso cansaço, seguros com a nossa devoção 
terminado o trabalho, sucumbimos

lançámo-nos directos em quartos calorosos

em direcção às histórias de ficção científica da democracia

e às suas canções, come gather 'round people for the times

say it loud and when you talk about destruction count me out deep in my heart I do believe

ohlord won't you buy me make me wanna holler

tudo bem, o álcool, as drogas,

dissemos que vivíamos já num outro tempo

e eles esperaram, vigiaram-nos, extirparam todas as letras boas das canções

do seu lado bom, da ciência, e o delicioso passou a ser mais do que, bom, mais, que difícil agora separar o que foi

do que fomos! 
como somos prisioneiros dos fantasmas deles!

como, nos seus princípios e nos seus fins, e não espanta, não espanta, cada tardinha se ponha em axiomas, os violinos dos medos comestíveis

chega alguém de negro, oh amor, meu amor, os eclipses nos vidros das janelas, a vida secreta da coroa do sol a passar

a mulher jaz na viela

traiçoeira e nua uma vez mais,

metade da mente assim se atrofia, como portas inertes e camiões do lixo, os sempre vivos centros comerciais de todos os desejos 
poucos anos, poucos para o planeta distante, como havíamos nós de saber, tão sustidos, indefesos nas nossas fomes, mordendo o coração até ao centro de mais sangue

como teria sido poder ter dançado com Celia Cruz, sério semblante,

ter estudado antes

os nomes das ruas de Montevideo ou Havana, de Kingston ou de Caracas, como se fosse para lá morar, no futuro elegante, como se nenhuma outra vida servisse, ou como se os votos de transformação fossem somente feitos em Parral ou Basse-Pointe

ter amado antes

Te recuerdo Amanda, la calle mojada

corriendo a la fábrica la lluvia en el pelo,

cantar esta canção a possíveis amantes 


\author{
depois ver Che \\ Guevara homem já velho na televisão \\ a voz inquebrável de Angela dissolveu as prisões, \\ morrer assim, nesta compaixão, \\ nunca ter escutado "Redemption Song" tão rouca, nunca \\ não desejar nenhum outro império a não ser o pulso da história \\ medido por outra mão, \\ tal como os continentes se voltam no seu sono \\ mecanismo engenhoso movido a ventos que de quando em vez \\ de imanes indiscretos que permitem \\ fendas imprevisíveis de uma incurável luz \\ agora, temos de esperar que eles fiquem exaustos, agora \\ é preciso rezar pelo seu declínio com mãos pontiagudas como facas, \\ com todos os brilhantes silêncios, \\ de forma a entender a linguagem toda, \\ toda a imaculada linguagem do mundo saqueado
}

Trad. Ana Luísa Amaral

NOTA

* Dionne Brand é uma reputada poeta, romancista e ensaísta, conhecida pela experimentação formal e pela beleza e premência da sua obra. Poeta socialmente comprometida, Brand é autora de uma obra premiada que inclui livros como Land to Light On (1997), thirsty (2002), Inventory (2006) e Ossuaries (2010). O seu livro mais recente, The Blue Clerk, um poema ensaio, foi distinguido com o Trillium Book Award. Theory (2018), o mais recente dos seus cinco romances, ganhou o Toronto Book Award. É autora da conhecida obra de não-ficção $A$ Map to the Door of No Return (2001) e o seu mais recente livro nesta área é An Autobiography of the Autobiography of Reading (2020). Dionne Brand é Professora na Universidade de Guelph, Ontário. 